\title{
An Open Source Exergy Calculator Tool
}

\author{
Juan M. Montelongo-Luna Brent R. Young William Y. Svrcek \\ Chemical \& Petroleum Engineering Department, University of Calgary \\ 2500 University Dr. NW Calgary AB T2N 1N4 \\ jmontelo@ucalgary.ca_byoung@ucalgary.ca_svrcek@ucalgary.ca
}

The constant tightening of environmental regulations and the ongoing need to reduce operating costs have posed a challenge for the design of any chemical process. Exergy is a potential indicator that can aid in the design of energy efficient chemical processes and plants. An open source exergy calculator has been created by embedding the calculation procedure in an open source chemical process simulator. This serves as a potential tool for design teams to quickly evaluate several process options in detail in order to understand their energy utilization. A simulation case study is presented to show the application of the tool.

\section{Introduction}

Process design has been always an extremely important step in the creation of a new chemical process or plant. The constant tightening of environmental regulations and the ongoing need to reduce operating costs have posed a challenge for the design of any chemical process; this is also the case for existing processes that have to be retrofitted to comply with the changing environmental regulations.

In process design the capabilities provided by computers (e.g. fast calculation, large data storage, logical decisions) allow engineers to solve larger problems and to do it much more rapidly; furthermore, with the aid of computer software the engineers' role can be shifted from problem solving to planning, conceiving, interpreting and implementing [1].

The intention of this article is to show the potential help obtained in process design by using the computational tools available to chemical engineers today and applying the concept of exergy as a means of finding the most inefficient parts of a given process or plant.

The concept of exergy is reviewed in the next section and from there the equations and procedure to calculate the exergy of a steady-state material stream within a chemical process simulator are presented. In section 3 the design of the exergy calculator is presented. In section 4 a typical gas dehydration plant is simulated using Sim42 [2] as the chosen process simulator. Then the exergy calculator tool is applied to the simulation to perform an energy analysis and "discover" the most inefficient parts of the simulated process. Numerical results for the case study are presented in section 5 .

\section{The exergy concept}

The most common analysis for energy efficiency of a plant or process is based on the First Law of Thermodynamics (i.e. Energy conservation balance). However, this analysis does not provide enough information regarding the potential work that a form of energy can produce or the potential work lost in energy transformation processes [3].

Exergy, however, is based on the First and Second Laws of Thermodynamics which allows accounting for irreversibilities in a process providing a more detailed tracking mechanism for the energy usage.

The Exergy of a stream of matter is defined by Kotas as the maximum amount of work obtainable when the stream is brought from its initial state to the dead state by (reversible) processes during which the stream may interact only with the environment [3]. Where the dead state is that of unrestricted equilibrium conditions of mechanical, thermal and chemical equilibrium between the system and the environment.

There are two main ways to calculate exergy. One divides exergy into physical and chemical components [4] and the other considers exergy as being composed of three components, namely physical exergy, chemical exergy and exergy change of mixing [5]. For the present work the latter approach was used to develop the software because it presents more advantages for composition-changing processes.

The advantages of considering exergy as being composed of three components is that the exergy components are calculated independently from each other and the calculation appeals to be clear with no "hidden" components in each step. So the exergy, B, is calculated via equation (1). 


$$
B=B_{\text {chem }}+B_{\text {phys }}+\Delta_{\text {mix }} B
$$

\section{Exergy components}

Exergy will be calculated as the sum of three components; chemical and physical exergy and the exergy change of mixing [5].

The chemical exergy is calculated based on the socalled standard chemical exergy for the chemical elements which can be calculated from standard formation enthalpy and Gibbs energy or obtained from standard tables [6]. Section 5 shows some numerical values for the standard chemical exergy of the elements used in the case study. Calculation of chemical exergy also requires a flash calculation at reference conditions. The chemical exergy is then given by equation (2).

$$
B_{\text {chem }}=L_{0} \sum_{i=1}^{n} x_{0, i} B_{c h e m, i}^{0 l}+V_{0} \sum_{i=1}^{n} y_{0, i} B_{c h e m, i}^{0 v}
$$

The Physical Exergy term requires a flash calculation at both the reference and the actual conditions. A mixing term is avoided by considering only the contribution of the pure components to the enthalpy and entropy of the mixture at reference and actual conditions. The physical exergy component is then given by equation (3).

$$
B_{p h y s}=\left[\begin{array}{l}
\left.L\left(\sum_{i=1}^{n} x_{i} H_{i}^{l}-T_{0} \sum_{i=1}^{n} x_{i} S_{i}^{l}\right)+\right]^{T, P} \\
V\left(\sum_{i=1}^{n} y_{i} H_{i}^{v}-T_{0} \sum_{i=1}^{n} y_{i} S_{i}^{v}\right)
\end{array}\right]_{T_{0}, P_{0}}^{T}
$$

For the determination of the Exergy Change of Mixing, the concept of "property change of mixing" is used; this is shown for an arbitrary thermodynamic property, $M$, in equation (4).

$$
\begin{aligned}
& \Delta_{m i x} M=L\left(M^{l}-\sum_{i=1}^{n} x_{i} M_{i}^{l}\right)+ \\
& V\left(M^{v}-\sum_{i=1}^{n} y_{i} M_{i}^{v}\right)
\end{aligned}
$$

Thus, enthalpy and entropy changes can be calculated to obtain the exergy change of mixing, which is the contribution due to the pure components being in a mixture, at actual conditions is calculated by applying equation (5).

$$
\Delta_{\text {mix }} B=\Delta_{\text {mix }} H-T_{0} \Delta_{m i x} S
$$

The necessary calculations can be easily done in a chemical process simulator which inherently performs thermodynamic calculations in a very efficient manner. The design of the exergy calculator and the implementation of these equations are presented in the next section.

\section{Exergy calculator tool}

As mentioned in the previous section, Exergy can be easily calculated with the help of a process simulator. For the present work Sim42 [2] was used as the chemical process simulator. Since Sim42 is an Open Source program, this permitted the seamless inclusion of the exergy calculations into the code of the simulator without having the inconvenience of linking any external computer routines to the simulator or writing a macro-like routine inside the simulator's own programming or scripting language. It is also freely available to any interested user or developer.

As mentioned before, the approach by Hinderink et al. [5] where the calculation of the exergy is divided into three components was implemented in the open source chemical process simulator Sim 42 to create the exergy calculator.

The exergy calculator performs the following steps in order to get the exergy of a material stream:

1. Identify the thermodynamic property package and the chemical species used in the simulation.

2. Identify which elements within the simulation represent material streams.

3. Calculate thermodynamic properties for each of the chemical species at standard conditions.

4. Get thermodynamic properties for each of the chemical species at actual conditions.

5. Calculate thermodynamic properties for the material streams at reference conditions.

6. Get thermodynamic properties for the material streams at actual conditions.

7. Calculate the chemical exergy component.

8. Calculate the physical exergy and the exergy change of mixing components.

9. Calculate the exergy for the material stream.

10. Display the results for the total exergy for each stream.

In $\operatorname{Sim} 42$ it is not necessary to have "Material Streams", instead, the information is propagated through "Ports". The "Material Port" represents streams of matter and it carries all the information regarding physical, chemical and thermodynamic properties [7]. 
The implementation for the exergy calculation was set up in the call to the thermodynamic property package. The "Exergy Property" was added to the Sim42 list of variables and then calculated in the thermodynamic provider interface. This allowed inserting the exergy into the material ports and propagating the values throughout the simulation.

It is worth noting that at actual conditions the exergy calculator just needs to take values for the thermodynamic properties already calculated by the "natural flow" of the process simulator. However, the values for the standard conditions need to be calculated because they are not included in the regular process simulator calculation steps. Notice also that the exergy calculator does not take into account energy streams modeled as pure or direct energy. In order to take the exergy of the utilities into account it is necessary to model them as the actual material streams they represent (e.g. high pressure steam, hot oil, etc.).

\section{Natural gas dehydration plant simulation}

A typical natural gas Tri Ethylene Glycol (TEG) Dehydration process has been selected as a case study for the purposes of demonstrating the exergy calculation tool.

Glycol dehydration is used to lower the water content of natural gas to prevent hydrate formation in the pipelines and downstream processes; TEG Dehydration is not the only process available but it is very common when the specifications to meet are not too stringent.

The process consists of an absorber operated at high pressure in which the water-saturated natural gas is contacted with recycled lean TEG, from this absorber the dry gas stream is sent to a heat exchanger where it takes some energy from the recycled TEG stream before this one enters the absorber. The rich TEG stream is passed through a J-T valve and then in a flash drum some of the water vapour and acid gas contents are taken out of the system to a separate processing unit. The liquid stream coming out of the flash drum is preheated in a heat exchanger and fed to the TEG regenerator where the water and the rest of the acid gas are taken away and the regenerated lean TEG sent back to the process. The regenerated TEG from the regenerator is passed through a heat exchanger where it preheats the regenerator feed. Make up TEG is added to the lean recycled TEG to counteract any TEG losses and then the recycled TEG stream is boosted to high pressure again before passing it through the heat exchanger before entering the absorber again.
From [8] a simplified typical configuration and operating conditions for a TEG Dehydration plant were selected. Table 1 shows the composition of the saturated lean natural gas coming in to the plant.

\begin{tabular}{cc}
\multicolumn{2}{c}{ Table 1. Inlet gas composition } \\
\hline Component & Mole fraction \\
\hline $\mathrm{N}_{2}$ & 0.00100 \\
$\mathrm{H}_{2} \mathrm{~S}$ & 0.01544 \\
$\mathrm{CO}_{2}$ & 0.02835 \\
$\mathrm{CH}_{4}$ & 0.89820 \\
$\mathrm{C}_{2} \mathrm{H}_{6}$ & 0.03098 \\
$\mathrm{C}_{3} \mathrm{H}_{8}$ & 0.01479 \\
$\mathrm{i}-\mathrm{C}_{4} \mathrm{H}_{10}$ & 0.00590 \\
$\mathrm{n}-\mathrm{C}_{4} \mathrm{H}_{10}$ & 0.00300 \\
$\mathrm{i}-\mathrm{C}_{5} \mathrm{H}_{12}$ & 0.00100 \\
$\mathrm{n}-\mathrm{C}_{5} \mathrm{H}_{12}$ & 0.00050 \\
$\mathrm{H}_{2} \mathrm{O}$ & 0.00086 \\
\hline
\end{tabular}

The main specifications for the computer simulation of the dehydration plant were as follows:

- Inlet gas pressure, $6200 \mathrm{kPa}$

- Inlet gas temperature, $303.15 \mathrm{~K}$

- Inlet gas flow, $500 \mathrm{kmole} / \mathrm{h}$

- TEG contactor pressure drop, $10 \mathrm{kPa}$

- $\quad$ TEG contactor theoretical stages, 8

- TEG contactor feed pressure, $6205 \mathrm{kPa}$

- TEG contactor feed temperature, $318.15 \mathrm{~K}$

- TEG contactor feed flow, $4.02 \mathrm{kmole} / \mathrm{h}$

- Dry gas temperature, $304 \mathrm{~K}$

- $\quad$ Sales gas temperature, $309.8 \mathrm{~K}$

- Low pressure rich TEG, $180 \mathrm{kPa}$

- $\quad$ TEG regen. feed temperature, $378.15 \mathrm{~K}$

- TEG regen. feed pressure, $110 \mathrm{kPa}$

- $\quad$ TEG regen. theoretical stages, 2

- $\quad$ TEG regen. reboiler temperature, $477.15 \mathrm{~K}$

- $\quad$ TEG regen. overhead temperature, $375.15 \mathrm{~K}$

- $\quad$ Pump feed pressure, $102.3 \mathrm{kPa}$

- $\quad$ Pump outlet pressure, $6275 \mathrm{kPa}$

The Peng-Robinson equation of state was used in the simulation as the thermodynamic property package. Notice also that the simulation case study was set up with no heat losses from any equipment to the environment and it was a rather idealized simulation. However, as it will be shown in the following sections even an idealized process has exergy losses and it is possible to identify the equipments in which these losses are larger.

Figure 1 shows a simplified diagram of the case study process. The results for the exergy calculation for 
every material stream in the simulated plant are

presented in the next section.

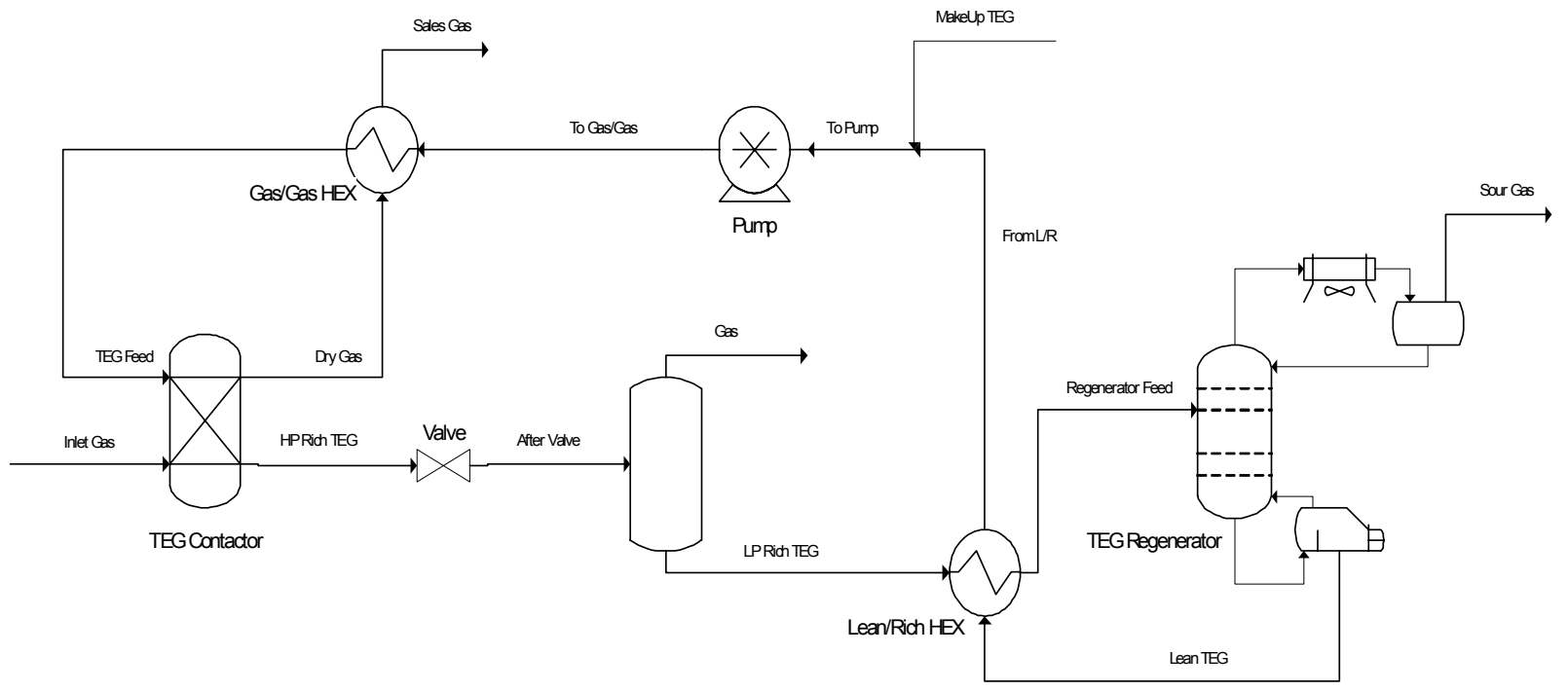

Figure 1. Natural gas TEG dehydration case study schematic

Based on the parameters described in the previous section the Exergy Tool was run on the case study

\section{Numerical results}

A very interesting topic for discussion with respect to the calculation of exergy is that of a reference state for the calculations. Several proposals for a reference state exist in the literature like $[3,9,10]$ and many of them are simply "arbitrary" decisions with a thermodynamic basis but no real meaning [6]. As can be expected, the selection of a reference state has an effect in the numerical values of the calculations. For this particular work it has been decided to use the reference state as given by van Gool [6], because it is believed that it has valid fundamental thermodynamic basis and practical meaning, especially for the chemical exergy of the elements. The reference pressure is $100 \mathrm{kPa}$ and the reference temperature is $298.15 \mathrm{~K}$. Table 2 presents the exergy values for the chemical elements used in the present case study. For details on the reference exergy values of a more complete set of chemical elements please refer to the work by van Gool [6].

$\begin{gathered}\text { Table 2. Reference exergy for selected } \\
\text { elements }\end{gathered}$
\begin{tabular}{cc}
\hline Element or Compound & Exergy, kJ/mole \\
\hline $\mathrm{C}$ & 394.4 \\
$\mathrm{H}_{2}$ & 235.7 \\
$\mathrm{~N}_{2}$ & 2.8 \\
$\mathrm{O}_{2}$ & 2.8 \\
$\mathrm{~S}$ & 632.5 \\
\hline
\end{tabular}
simulation to obtain the exergy numerical values. Table 3 summarizes the exergy flows of the most important material streams in the plant.

Table 3. Material streams exergy

\begin{tabular}{lcc}
\hline \multicolumn{1}{c}{ Stream } & $\begin{array}{c}\text { Exergy, } \\
\text { kJ/kmole }\end{array}$ & $\begin{array}{c}\text { Exergy } \\
\text { flow, kW }\end{array}$ \\
\hline Inlet gas & $8.158 \times 10^{5}$ & $1.196 \times 10^{5}$ \\
TEG feed & $3.273 \times 10^{6}$ & $3.654 \times 10^{3}$ \\
Dry Gas & $8.605 \times 10^{5}$ & $1.195 \times 10^{5}$ \\
Sales Gas & $8.605 \times 10^{5}$ & $1.195 \times 10^{5}$ \\
HP rich TEG & $2.862 \times 10^{6}$ & $3.705 \times 10^{3}$ \\
After Valve & $2.860 \times 10^{6}$ & $3.702 \times 10^{3}$ \\
Gas & $7.657 \times 10^{5}$ & $3.600 \times 10^{1}$ \\
LP Rich TEG & $2.939 \times 10^{6}$ & $3.666 \times 10^{3}$ \\
Regen. Feed & $2.942 \times 10^{6}$ & $3.670 \times 10^{3}$ \\
Sour Gas & $1.226 \times 10^{5}$ & $1.600 \times 10^{1}$ \\
Lean TEG & $3.285 \times 10^{6}$ & $3.668 \times 10^{3}$ \\
From L/R & $3.277 \times 10^{6}$ & $3.659 \times 10^{3}$ \\
MakeUp TEG & $3.503 \times 10^{6}$ & $2.900 \times 10^{-1}$ \\
To Pump & $3.277 \times 10^{6}$ & $3.660 \times 10^{3}$ \\
To Gas/Gas & $3.279 \times 10^{6}$ & $3.662 \times 10^{3}$ \\
\hline
\end{tabular}

It is worthwhile to remark that there are some energy streams in the simulation that are not taken into account by the exergy calculator as they were modeled as direct energy inputs to the system (i.e. no exergy loss in them).

Table 4 shows the inlet and outlet exergy flows for each of the main equipment in the process simulation. 
Table 4. Equipment exergy flows

\begin{tabular}{lcc}
\hline \multicolumn{1}{c}{ Equipment } & $\begin{array}{c}\text { Exergy in, } \\
\mathbf{k W}\end{array}$ & $\begin{array}{c}\text { Exergy out, } \\
\mathbf{k W}\end{array}$ \\
\hline TEG contactor & $1.233 \times 10^{5}$ & $1.232 \times 10^{5}$ \\
Gas/gas HEX & $1.232 \times 10^{5}$ & $1.232 \times 10^{5}$ \\
Valve & $3.705 \times 10^{3}$ & $3.702 \times 10^{3}$ \\
Flash drum & $3.702 \times 10^{3}$ & $3.702 \times 10^{3}$ \\
Lean/Rich HEX & $7.334 \times 10^{3}$ & $7.329 \times 10^{3}$ \\
TEG Regen. & $6.090 \times 10^{3}$ & $5.343 \times 10^{3}$ \\
Pump & $3.661 \times 10^{3}$ & $3.662 \times 10^{3}$ \\
\hline
\end{tabular}

Fuel gas, with a composition similar to that of the Sales gas stream, at a pressure of $120 \mathrm{kPa}$ and a temperature of $298.15 \mathrm{~K}$ was used as the fuel for the fired heaterreboiler for the TEG regenerator; air at a temperature of $293.15 \mathrm{~K}$ and a pressure of $120 \mathrm{kPa}$ was used as the source of oxygen for the fired heater. For the Pump the energy input was an exergy flow (i.e. it was assumed to be electrical energy at $100 \%$ efficiency).

The following section deals with the interpretation of the results and a discussion of the exergy calculator tool.

\section{Discussion}

The results shown in Table 3 along with the exergy of the utilities are the values needed to carry out a simple exergy analysis. Table 4 shows where the exergy losses are larger; thus, allowing to search for alternatives for improvement.

For the case study it can be seen that the equipment where the most exergy is lost are the TEG contactor and the TEG regenerator. This has to do with the multiple separation stages inside these equipments. This cannot be changed in the actual process since a predefined degree of separation is needed; however, a more detailed analysis within the TEG regenerator could lead to find the places inside the column where the exergy is being lost (besides the separation stages). One possibility could be the heating medium for the reboiler; if the temperature difference is too large the exergy loss will be large.

The pump offers an excellent example of how the prediction of thermodynamic properties could affect the exergy calculation. The strange values obtained for the pump can be attributed to the fact that the PengRobinson equation of state has been used and the pump handles almost pure TEG (i.e. this equation of state is not the best choice for those conditions).
The flash drum presents a constant exergy flow because the actual exergy loss happened in the valve just before it.

The heat exchangers are the best example to show that even when an ideal model (e.g. an adiabatic heat exchanger) is used there is an exergy loss which is due to the irreversibility of the process. In the heat exchanger example this happens because of the heat transfer over a finite temperature difference.

From the design point of view the analysis over a heat exchanger could be used to find the best combination of temperature difference and heat transfer area (capital cost) that minimizes the exergy loss (i.e. maximize efficiency).

\section{Conclusions}

It has been shown that the exergy can be easily calculated with the aid of a chemical process simulator (Sim42). The results provided from this simple exergy analysis show the areas where the exergy consumption is the greatest, thus allowing for improvement.

There is a potential for applying exergy calculations into the early stages of process design to take into account inefficiencies so that the design engineers can take actions to correct them. It is also evident that this approach can be used in retrofitting industrial processes as it can give a better perspective on where the energy is being wasted. Embedding the exergy calculation into a process simulator created a tool that can be extensively used in the early stages of process design to rapidly evaluate different scenarios to find the most energy efficient ones.

Open source code allows anyone to take the program and look the actual "machinery" that performs the calculations. This has the potential to improve the current implementation of the exergy calculator tool and get a better understanding of the calculation procedure.

The natural gas dehydration plant case study showed the advantages of performing an exergy analysis. It allowed rapid identification of the equipment where the largest exergy losses were and also showed that even an ideal model has irreversible processes.

This tool was developed as an integral part of a chemical process simulator (Sim42) to take advantage of the process simulator design. This permitted implementation of the best approach to integrate the exergy calculation into the process simulator. 


\section{Acknowledgments}

JMML wishes to thank Raul Cota for helpful discussions on Sim42's design. This work was in part supported by the COURSE program from the Alberta Energy Research Institute under the agreement No. 1512 .

\section{Notation}

$\begin{array}{ll}\text { B } & \text { Exergy } \\ \mathrm{H} & \text { Molar enthalpy } \\ \mathrm{L} & \text { Liquid fraction } \\ \mathrm{M} & \text { Arbitrary thermodynamic property } \\ \mathrm{n} & \text { Total number of compounds } \\ \mathrm{P} & \text { Pressure } \\ \mathrm{S} & \text { Molar entropy } \\ \mathrm{T} & \text { Temperature } \\ \mathrm{V} & \text { Vapour fraction } \\ \mathrm{x} & \text { Liquid molar fraction } \\ \mathrm{y} & \text { Vapour molar fraction }\end{array}$

\section{Greek}

$\Delta$

$\begin{array}{ll}\text { Subscripts } & \\ 0 & \text { Standard conditions } \\ \mathrm{i} & \text { Compounds } \\ \text { chem } & \text { Chemical } \\ \text { phys } & \text { Physical } \\ \text { mix } & \text { Mixture }\end{array}$

$\begin{array}{ll}\text { Superscripts } & \\ 0 & \text { Standard conditions } \\ 1 & \text { Liquid phase } \\ \text { v } & \text { Vapour phase }\end{array}$

\section{References}

[1] Peters, M.S. and K.D. Timmerhaus, Plant design and economics for chemical engineers, 4th ed., McGrawHill, 1991.

[2] VMG, Sim42, www.virtualmaterials.com/sim42, last accessed on May 2, 2005.

[3] Kotas, T.J., The exergy method of thermal plant analysis, Butterworths, London, 1985.

[4] Kotas, T.J., "Exergy Concepts for Thermal Plant", International Journal of Heat and Fluid Flow, MEP Ltd., 1980, pp. 105-114.

[5] Hinderink, A.P., F.J.P.M. Kerkhof, A.B.K. Lie, J. De Swaan Arons, and H.J. Van Der Kooi, "Exergy analysis with a flowsheeting simulator - I. Theory; calculating exergies of material streams", Chemical Engineering Science, Pergamon Press Inc., Tarrytown, NY, USA, 1996, pp. 4693-4700.

[6] Van Gool, W., "Thermodynamics of chemical references for exergy analysis", Energy Conversion and Management, Elsevier Science Ltd., 1998, pp. 17191728.

[7] Cota Elizondo, R.C., Development of an open source chemical process simulator, M.Sc. Thesis, University of Calgary, Calgary, AB, 2003.

[8] GPSA, Engineering Data Book, 11th ed., Gas Processors Suppliers Association, Tulsa, OK, USA, 1998.

[9] Ahrendts, J., "Reference states", Energy, Pergamon Press Ltd., 1980, pp. 666-677.

[10] Szargut, J., D.R. Morris, and F.R. Steward, Exergy analysis of thermal, chemical, and metallurgical processes, Hemisphere, New York, 1988. 